\title{
BMJ Open Attitudes of rural communities towards the use of technology for health purposes in New Zealand: a focus group study
}

\author{
Duncan R Babbage (D) , ${ }^{1}$ Kirsten van Kessel (D) ,2 Agnes Terraschke, ${ }^{1}$ \\ Juliet Drown (D) , ${ }^{1}$ Hinemoa Elder (D) ${ }^{3}$
}

To cite: Babbage DR, van Kessel K, Terraschke A, et al. Attitudes of rural communities towards the use of technology for health purposes in New Zealand: a focus group study. BMJ Open 2020;10:e037892. doi:10.1136/ bmjopen-2020-037892

- Prepublication history for this paper is available online. To view these files, please visit the journal online (http://dx.doi. org/10.1136/bmjopen-2020037892).

Received 10 March 2020 Revised 06 May 2020 Accepted 07 May 2020

D) Check for updates

(c) Author(s) (or their employer(s)) 2020. Re-use permitted under CC BY-NC. No commercial re-use. See rights and permissions. Published by BMJ.

${ }^{1}$ Auckland University of Technology, Centre for eHealth, Auckland, New Zealand

${ }^{2}$ Centre for eHealth \& School of Public Health and Psychosocial Studies, Auckland University of Technology, Auckland, New Zealand

${ }^{3}$ Brain Research New Zealand, The University of Auckland, Auckland, New Zealand

Correspondence to Dr Kirsten van Kessel; kvankess@aut.ac.nz

\section{ABSTRACT}

Objectives Examine attitudes to using online health and wellness services, and determine what barriers may exist to this in two rural communities in New Zealand.

Design $A$ thematic analysis informed by a social constructivist paradigm explored the attitudes of youth and adults to give voice to these communities. Eighteen focus groups-nine in each region-were held for an hour each, with between three and nine participants in each group. Setting Two rural areas at the Northern and Southern ends of New Zealand were chosen. In each area, we partnered with a local health centre providing primary care services. Three localities were identified within each region where we conducted the data collection.

Participants Participants were youth aged $12-15$ years, aged 16-20 years and adults over 21 years. Overall, 74 females and 40 males were recruited. Recruitment occurred through schools, community organisations or personal contacts of the facilitators, who were youth workers in their respective communities. Ethnicity of the participants was representative of each area, with a higher percentage of Māori participants in Northland.

Results Eight themes were identified which described participants' attitudes to technology use in healthcare. Themes covered accessibility, cost, independence, anonymity and awareness issues: technology makes health information easily accessible; access to technology can be limited in rural communities; technology can reduce the cost of healthcare but it is too expensive for some; technology increases independence and autonomy of people's own health; independent healthcare decisions come with risks; anonymity encourages people to seek help online; technology can help raise awareness and provide peer-support for people with health issues; technology impacts on social relationships.

Conclusions Participants-particularly youth—were generally positive about the role of technology in healthcare delivery, and interested in ways technology could improve autonomy and access to health and wellness services.

\section{INTRODUCTION}

Access to healthcare is limited in rural communities due to their remote locations. Rural residents often need to travel long
Strengths and limitations of this study

- In-depth qualitative information based on 18 focus groups, comprising 114 participants, a sizeable sample for a qualitative focus group study.

- Twelve of these focus groups were with rural youth who face particular challenges in rural locations, with fewer transport options and often socioeconomic disadvantage.

- Data drawn from two demographically different rural environments - in Northland and in Southland, New Zealand.

- A limitation of this work was that the broad nature of the indicative questions used in the focus groups may have reduced the specificity and depth of data that could have been obtained in any one topic area.

distances to medical appointments. ${ }^{12}$ Travel time and costs, lost earnings and possible accommodation costs create a higher financial burden compared with urban areas even when health services are free. ${ }^{3}$ These difficulties are particularly pronounced in vulnerable groups who experience higher levels of socioeconomic deprivation, such as the elderly and the unemployed, ${ }^{2}$ and tend to impact on the young. Mental health in rural areas is also an area of concern with service provision being challenging due to availability and accessibility and often stigma which is amplified in a small community. ${ }^{4}$

Recruitment and retention of rural health professionals is problematic worldwide. ${ }^{15}$ Multiple rural areas in New Zealand, including Northland and Southland, are classified by the Ministry of Health as hard-to-staff areas for general practitioners (GPs) and the Ministry runs a voluntary scheme to attract newly qualified GPs. ${ }^{6}$ In New Zealand, a high proportion of rural GPs are male, nearing retirement and work more hours than their urban colleagues. ${ }^{7}$ Having fewer available 
practitioners can mean rural residents are required to travel further to access healthcare.

Multiple systematic reviews focused on the rural communities of developed countries have consistently shown lower screening rates and later detection of cervical, prostate and breast cancers. ${ }^{8-10}$ These findings exemplify the impact of challenging access and understaffed services in rural communities due to the financial burden and travel required to receive medical services. Improvements in service provision continue to be a dilemma for health authorities around the world. ${ }^{1112}$

\section{Types of health technology}

In this study, technology has been broadly defined and includes telehealth, e-Health and m-Health although this is not an exhaustive list. 'Telehealth' consultations can be defined as systems for the exchange of visual and audio information to deliver treatment over distances. ${ }^{13} 14$ The term 'e-Health' or electronic health in a broad sense, refers to the use of the internet for health purposes including, for example, social media websites such as Facebook and Twitter for health promotion, communication and to promote programmes and services. ${ }^{15}$ 'm-Health' or mobile health, refers to the use of a handheld mobile device such as a smartphone or tablet to assist the delivery of healthcare. These devices can be used for audio or video calls, text and picture messages, and access to the internet and medical software such as books and quick guides. ${ }^{16}$

\section{Effectiveness of health technologies}

There is a growing body of evidence to support the notion that technology for health is beneficial. Telehealth has been shown to enhance access to high-quality healthcare, reduce travel time, costs and disruption to patients' lives due to monitoring at home. ${ }^{12} 17$ Health-focused social media groups have been reported in multiple systematic reviews to be effective in providing support and sharing quality information regarding general health issues such as cardiovascular disease. ${ }^{1819}$ A study of general practices in the UK found that just under half of GP practices in a county in the UK have a publicly accessible Facebook page $^{20}$ and recently, Crilly et $a l^{21}$ reported that over three-quarters of community pharmacists surveyed in London $(\mathrm{n}=202)$ would promote a social media health page created by health professionals. Email has been effectively used to communicate with medical practices for repeat prescriptions, appointment bookings and obtaining test results. ${ }^{22}$ Furthermore, internet-based cognitive behavioural therapy for post-traumatic stress disorder and videoconferencing therapy for substance misuse were both found to be at least as good as face-toface therapy. ${ }^{132324}$

\section{Utilisation is low}

Despite technology use for health purposes being effective and able to improve to access issues in rural areas, uptake has been slow. ${ }^{25}$ Even when video-based consultations were provided free of charge in Australia, utilisation was low. ${ }^{14}$ Barriers to the use of social media for health benefits include access to devices, perceived acceptability of interventions and lack of monitoring of the online environment. ${ }^{26}$ To increase the use of technology and to view its use more favourably, Musiat $e t a l^{25}$ suggest that raising awareness of positive research outcomes among clinicians and service users will make a difference, especially in the e-mental health arena.

\section{Attitudes towards technology for health}

More recently, there is an emerging body of evidence to suggest that the general public view technology as acceptable. Welch $e t a l^{26}$ compiled an overview of eleven systematic reviews of the use of social media to promote health equality and concluded that participants viewed the use of social media for support and finding information positively.

Mental health interventions are also available on the internet but the evidence around acceptability of internet therapies for mental health is mixed. For instance, Wootton et $a l^{27}$ investigated this in an internet-based treatment for adults with obsessive compulsive disorder. Eighty-one per cent of participants thought they would see at least a small improvement in their symptoms suggesting high acceptability of this treatment. In another study involving adults seeking treatment for depression or anxiety, Carper et $a l^{28}$ reported that their participants had slightly negative views of computer-based mental health therapy. A recent study of young adults' use of a mental health and wellness website identified that acceptance and support of these types of sites was high and the most important criteria contributing to their likely use was the perception of helpfulness. ${ }^{29}$ However, the majority of such studies examining attitudes towards technology for health come from international studies focused on nonrural or general populations.

\section{Current study}

This study explores the attitudes towards the use of technology in healthcare in two rural communities within the Northland and Southland districts of New Zealand. Northland is home to $3.6 \%$ of New Zealand's population, with $32 \%$ of residents identifying as Māori, compared with $14.9 \%$ for all of New Zealand. At the time of the 2013 New Zealand Census, unemployment in Northland was $9.7 \%$, higher than the national average $(7.1 \%)$ with a median income lower than the national average. Southland is home to $2.2 \%$ of New Zealand's population, $13 \%$ of whom identify as Māori. Unemployment was lower than the national average at $4.7 \%$ and the median income was approximately the same as the national average. ${ }^{30}$

Healthcare in New Zealand is primarily provided through a public health system that is free at the point of delivery for secondary and tertiary services. Primary healthcare is provided through privately owned general practices, but services are subsidised-such as with substantial subsidies for prescription medicines, as well 
as the consultation costs for children, people on low incomes, high service users and for all New Zealanders when receiving treatment after accidental injuries.

At the time of the 2013 census, $77 \%$ of New Zealand households had access to the internet, however, both Northland and Southland sit below this average at $68 \%$ and $71 \%$, respectively. Access to cell phones was also lower for the rural communities where the national average was $84 \%$, but $80 \%$ in the Northland district and $83 \%$ in Southland district. Across New Zealand, only 1.6\% of households had no access to any form of technology, cell phone, landline, fax machine or internet. ${ }^{30}$

\section{METHOD}

A qualitative explorative study that used thematic analysis informed by a social constructivist paradigm, exploring the attitudes of youth and adults in two rural communities towards using technology for health purposes. This method was chosen to give a voice to the community and add to the body of knowledge about whether this type of intervention is acceptable to rural populations in New Zealand. The two rural areas chosen are situated at either end of the country. Focus groups were hosted in three localities within the Northland region. Likewise, in the South, focus groups were hosted in three localities in the Southland region.

The research team consulted and developed a partnership with a healthcare organisation in each research location. One of the research team members (HE) also had iwi (tribal group) connections in Northland which were important in developing relationships with the community there. The focus group facilitators were members of local communities who were initially recommended through the healthcare organisations, and the Northland facilitator identified as Māori. Both facilitators were involved in youth work in their respective communities and when approached about possibly working with the project, showed strong interest in being involved. The facilitators were paid by the research team for their time working in the study. The facilitators were given training in focus group facilitation for this study, by members of the research team at Auckland University of Technology, to develop their skills and improve the consistency of the study. Due to their prior involvement with youth in their communities, both facilitators knew the participants of one of the youth focus groups in their location. Participants in other groups may have been known, less well known or unknown to them. Considering the nature of living in small rural locations, it was unavoidable that participants may have known or recognised the facilitators. The analysis of the data was done by a researcher (AT) who was not present at the interviews and did not belong to any of the communities, removing the possibility of being swayed by opinions embedded in the local context.

\section{Patient and public involvement}

The development of the research questions was informed by participant experience and priorities through the collaboration with the two partner health organisations, located in the regions this study focused on. Early design and content meetings were held in each location between members of the research team and representatives from the organisations at their offices. The health organisation representatives suggested areas to focus on, affirmed age ranges of participants and suggested suitable people to take on the facilitator roles in their communities. At the completion of the study, participants who had given their contact details received a summary of the findings either via email or post.

\section{Participants}

Seventy-four female and forty male participants were recruited across the two rural settings, through personal contacts of the research assistants (often through a key person in an organisation or community group), posters in local schools and health centres, word of mouth snowball sampling and in one location, through an article about the research in the local newspaper. Potential participants contacted the focus group facilitator in their location if they wished to participate and were given a Participant Information Sheet to read with full details about the study.

Eighteen focus groups were held with between three and nine participants in each. Groups were divided by age as this is a strong determinant of technology use. The age groups were 12-15 years, 16-20 years and over 21 years. Of the 41 participants in the 21+ age group, only eight were over 50 years old including two participants over 70 years old, representing the upper limit of the range. Three different groups were held per age bracket in Northland and in Southland (see table 1).

As seen in table 1, the ethnic and occupational backgrounds of focus group participants indicate a higher percentage of Māori or bicultural participants in Northland $(72 \%)$ and a higher unemployment rate $(28 \%)$ compared with Southland (Māori or bicultural 21\%, unemployment 2\%). In our study, Māori were deliberately oversampled in Northland given our interest in obtaining the views of this important population who are often under-served by health services.

\section{Focus groups}

Focus groups were held in community facilities in each location. Groups in Northland used local medical centre and community meeting rooms in three different locations. In Southland, school meeting rooms were also used. The average length of time for a group was $47 \mathrm{~min}$, with the range being $25-84 \mathrm{~min}$. At the start of each focus group, the facilitator introduced themselves and provided a brief description of the research and why it was being carried out, demographic information was collected, confidentiality was discussed and consent forms were signed. Written consent was provided by a parent for participants under 16 years of age. Semistructured, openended questions were used to enquire about participants and their whānau (extended family) experiences using 
Table 1 Participant demographic characteristics

\begin{tabular}{|c|c|c|c|}
\hline Age and gender & Northland & Southland & Total \\
\hline \multicolumn{4}{|l|}{$12-15$ years } \\
\hline Male & 8 & 6 & 14 \\
\hline Female & 10 & 7 & 17 \\
\hline \multicolumn{4}{|l|}{$16-20$ years } \\
\hline Male & 7 & 5 & 12 \\
\hline Female & 14 & 16 & 30 \\
\hline \multicolumn{4}{|l|}{$21+$ years } \\
\hline Male & 6 & 8 & 14 \\
\hline Female & 13 & 14 & 27 \\
\hline Total & 58 & 56 & 114 \\
\hline Ethnicity & $\begin{array}{l}\text { Northland, } \\
(\%)\end{array}$ & $\begin{array}{l}\text { Southland, } \\
(\%)\end{array}$ & Total \\
\hline NZ European & $14(24)$ & $41(73)$ & 55 \\
\hline Māori & $33(57)$ & $9(16)$ & 42 \\
\hline $\begin{array}{l}\text { Bicultural background } \\
\text { (NZ Māori \& European) }\end{array}$ & $9(15)$ & $3(5)$ & 12 \\
\hline Other* & $2(3)$ & $3(5)$ & 5 \\
\hline Total & 58 & 56 & 114 \\
\hline Employment status & Northland & Southland & Total \\
\hline Attending high school & $27(47)$ & $21(38)$ & 48 \\
\hline Further study & $2(3)$ & $6(11)$ & 8 \\
\hline Unemployed & $16(28)$ & $1(2)$ & 17 \\
\hline Employed & $8(14)$ & $21(38)$ & 29 \\
\hline Homemaker & $3(5)$ & $1(2)$ & 4 \\
\hline Self employed & 2 (3) & $4(7)$ & 6 \\
\hline Retired & 0 & $2(3)$ & 2 \\
\hline Total & 58 & 56 & 114 \\
\hline
\end{tabular}

*includes Latin America, Europe, Samoa and the Cook Islands. NZ, New Zealand.

technology related to healthcare, whether it was helpful, relevant and any barriers they perceived to technology being used. Field notes were not taken during the focus groups. Indicative focus group questions were:

- How do you think technology could help people living here take positive steps towards health?

- What are some factors or reasons which might lead you to try to use technology to support being healthier?

- What might prevent or stop you or other people from using technology in this way?

- What could be done to overcome that barrier?

- If you were going to use a technology-based health programme, what would it look like?

All participants received a NZ\$30 (€18) voucher and shared a meal after the group to thank them for their participation and in recognition of distance travelled to participate. One Southland participant gave written consent to participate, then left to collect a child from school before the group had commenced and did not return. No data were collected for this participant. No other participants withdrew from the study.

\section{Analysis}

Focus groups were audio recorded and then transcribed by a professional transcriber. The data were analysed using thematic analysis. This analytical method permits an exploratory examination and provides a detailed and rich account of participant data and it is useful for analysing, identifying and reporting themes inside data and enables the reporting of the reality, meanings and experiences of participants. ${ }^{31-33}$ Through multiple readings of the transcripts, themes were derived and summarised. Microsoft Excel and Word were used in the data coding and derivation of themes by preference and prior experience of the researcher who carried out the coding work (AT). Themes are reported at a focus group level and illustrative quotes have been included. All quotes are taken from focus group participants who are unidentified.

\section{RESULTS}

Eight themes were identified which described participants attitudes to technology use in healthcare:

- Technology makes health information easily accessible.

- Access to technology can be limited in rural communities.

- Technology can reduce the cost of healthcare but is too expensive for some.

- Technology increases independence and autonomy of people's own health.

- Independent healthcare decisions come with risks.

- Anonymity and privacy encourage people to seek help online.

- Technology can help raise awareness and provide peer-support for people with health issues.

- Technology impacts on social relationships.

Each theme is defined and elaborated below.

\section{Theme 1: technology makes health information easily accessible}

The easily accessible nature of technology was a strong theme across all age groups and both locations. Participants noted the ease of using smartphones to access medical information or call for help in emergencies.

Having it handy like you know being in bed and just wanting to search up something and it's on your phone. Having it so accessible. (Group 11, 16-20 years)

Easy access to health information was considered especially important in rural areas where there is less access to doctors and often significant distances to travel to see a health professional. Participants noted that technology can help avoid unnecessary trips to the doctor as patients can google their symptoms or call to discuss the situation before travelling to see the doctor face to face. 
Whereas when $[\ldots]$ we can look it up on the internet and it'll tell you whether [...] we do need to see a doctor or we don't need to see a doctor half the time [...] 'Cause if you just follow the procedure off the internet, that actually works half the time. [...] Yeah, save a 40 min drive - (Group 5, 21+years)

While most participants discussed access in relation to medical care, there were also comments about the use of a fitness app for exercise instead of travelling to a community gym:

Like if I did a fitness app I wouldn't have to like go to the gym or something, travel to the gym. (Group 18, 16-20 years).

One 12-15year old participant suggested that technology could potentially be helpful for people with transportation issues, such as older people with impaired vision or who are physically disabled:

people that, like, don't have much transport, like oldies that don't have, like, good enough vision to drive or anything, um it would help them take care of themselves, without having to, like, go ask people to drive, or something like that (Group 14, 12-15 years).

One participant (group 12, 21+ years) shared that Skype counselling is already available at their place of work as a means to assist people who cannot come in to meet an on-site counsellor.

The easy accessibility of technology was described variously as convenient, appealing and available anytime anywhere.

\section{Theme 2: access to technology can be limited in rural communities}

Easy access to healthcare via technology is not experienced by everyone as participants from nine focus groups considered reception issues, power cuts and slow internet to be barriers. Poor cell phone reception was mentioned as an issue by groups in both Northland and Southland, with a few groups reporting regular power cuts in their area. Participants associated access difficulties with their hesitance to rely on technology:

but what's going to happen if we can't use any technology and you become reliant on it all the time? Because when we have our power cuts you should see everyone going "Oh we're not going to have Facebook." (Group 2, 21+years)

Many participants thought that people being unfamiliar with technology was a major barrier to its use for health purposes in rural areas. A lack of understanding and experience was attributed to older users who grew up at a time when current technology was not available, technology was not as easily accessible as it is now and who have since not felt the need to learn. One participant considered that this age group may not benefit much from health-focused technology: for older family, they don't really know how to use much technology, so it's hard for them [...] if it (health services) does end up going to a more technology side of things, they're not going to benefit from that. (Group 18, 16-20 years)

Another participant describes a similar situation with a parent's struggle with technology use and a preference for calling people on the phone:

My dad is [over 60 years old] and he has a phone, however he absolutely hates texting $[\ldots]$ he doesn't know how to use a computer or a touch screen phone or anything like that. He just has a very simple phone for just calling and texting when he has to. (Group 4, $16-20$ years)

Other barriers to technology use included misplacing the device, batteries going flat (group 17, 16-20 years) and having no interest in using technology (group 8, $21+$ years). Some participants suggested solutions such as courses that teach older people to use technology (group $16,21+$ years) or a person who drives around with a device and helps connect people to Skype appointments.

Many participants expressed a preference for face-toface interactions with health professionals in the first instance and thought of technology as an adjunct to mainstream healthcare, although this was predominantly expressed by older participants.

I think that face-to-face when you've got that connection with somebody and you feel comfortable, it's like, 'Yeah, I'll come'. But when it's through technology sometimes that's a barrier. It's like, 'Oh, yeah, whatever'. It's too easy to delete. [...] that first port of call really needs to be a face-to-face type of thing. And then have it in an environment that's not so clinical. (Group 16, 21+years)

\section{Theme 3: technology can reduce the cost of healthcare but is too expensive for some}

Many participants in both regions considered technology a 'free' or cheap option compared with the cost of travel and doctor's fees. However, for others the high costs of internet usage were a major barrier to using technology for health-related purposes especially if a person did not own a smart phone or computer or have easy access to an internet connection. One participant illustrated how the cost of internet access is a major challenge for people who are unemployed:

it's quite expensive, and, I mean, if you're unemployed and you have to pay for internet, that's NZ $\$ 80$ [€48] a month, [...] some people can't afford that. And even to have it on your phone, you're still got to pay-get a phone card. That's what, NZ\$20 $[€ 12]$ and you only get so many megabytes [...] So not everyone can afford to be doing that. (Group 5, $21+$ years) 
Another participant described the substantial expense of satellite internet as they were situated outside of mobile coverage areas. Other participants discussed the potentially high costs associated with replacing devices if they were lost which convinced them to leave their devices at home.

\section{Theme 4: technology increases independence and autonomy over people's own health}

Participants discussed the benefits of being able to make independent decisions about healthcare without consulting a doctor. The main point that participants made in this discussion was that technology enables people to be more in control of their own health through education and self-management. One participant commented:

I'm just saying I would rather go to an app than being told what to do. (Group 1, 16-20 years)

The sense of independence in researching health online goes beyond a reluctance to be directed by a medical professional. In one discussion, participants talk about using a website to assess your mental health status. One participant commented that it allowed you to think about your issues in your own time:

You can do it on your own time. When you feel ready because like you might feel ready to go to the doctor but once you get there you might freak and go, like, and yeah it's completely on your own terms whether or not, which can be really important to some people (Group 3, 12-15 years)

Another participant continues the discussion, adding independence from parents:

And some people have to work independently. And they don't like having to rely on their mother to help them $[\ldots]$ so they can go deal with it themselves (Group 3, 12-15 years)

Technology can foster a person's sense of control over a medical condition through online research, which may also provide reassurance. A participant illustrated the reality of this in this quote :

Mostly it's your kids, you know if your kids have got a fever and blotches and you have a thousand questions or a million. For most of us it's like, excessive bleeding! Oh my god, type it in. Oh its ok, don't worry about it, it's common. (Group 2, 21+years)

This was echoed by a participant in another group who shared that a huge motivation for using technology for health purposes was to get a sense of what is normal:

Just being like 'am I OK?' That's probably just the biggest motivator for so many people just like, just wanting to know yourself, so reassurance. That's what's motivated me to do any of the stuff that I have done online to like try and find something. Just like 'how can I make this better?' (Group 11, 16-20 years)
Technology was also mentioned as an aid for managing a healthy lifestyle such as tracking health statistics like heart rate, weight, nutritional intake and exercise as well as managing medical conditions or learning difficulties. One parent participant explained a son's situation where he needs a computer at school:

[...] He doesn't know how to write, like, 'cos he has trouble spelling and that. But he's - finds it easier to type things up on the computer. (Group 5, 21+years)

In these examples, participants highlighted how technology and the wealth of information available online can help people gain knowledge about health bringing a sense of reassurance and control over their own medical condition or health status.

\section{Theme 5: independent health care decisions come with risks}

Participants in many groups expressed concern about making independent decisions based on online health information. Participants suggested there was a chance of either overestimating or underestimating a risk and therefore any information relating to whether they needed to see a medical professional could be misinterpreted by lay people.

Equally as dangerous if you've got something really bad but Google says that you're fine. [...] Like, that'd be even worse, wouldn't it? [...] Google says, Oh, yeah, sweet as, it's just a freckle. (Group 12, 21+years)

Similarly, some participants wanted feedback from a professional about the data entered into apps such as diet and heart rate. Others appreciated the interactive nature of health-focused Facebook pages where real people could respond and give advice.

I think it's important again the real person behind the technology. Because if you go just with the technology it's only the information in front of you but you don't have feedback. (Group 13, 21+years)

These views were more often cited by the older age group participants; participants in the 12-15years old focus groups were least likely to express concerns about gaining health information online.

The reliability of content was an important issue and participants pointed out that when self-diagnosing you may be presented with the worst-case scenario online which can lead to unnecessary worry. In the same way they felt that people may be able to convince themselves that their symptoms are harmless and do not warrant checking by a health professional. The uncertainty surrounding both the content and the author of a page where identity is unknown, was cause for concern to some participants.

\section{Theme 6: anonymity and privacy encourage people to seek help online}

The benefits of being anonymous online were mentioned especially in relation to sensitive and potentially 
stigmatising health issues such as mental or sexual health conditions.

You wouldn't want to go somewhere where everyone could see that you had a problem or going to the counsellor at school is kind of scary for some people so if there was something like online that they could do by themselves then no-one would know that. (Group 11, 16-20 years).

This was echoed by two other participants in another group:

Yeah so, but a lot of people aren't very good at talking or don't like talking face to face because...

Because talking is scary. (Group 3, 12-15 years)

Participants in the 16-20years bracket were concerned about the possibility of having their privacy breached online. Some participants worried that their information could be leaked through schools potentially monitoring students' internet use or having pages they have looked at coming up on their social media newsfeeds. This was discussed as a strong motivator to stop using apps.

Privacy is probably definitely a big one [...] let's say for instance a hypothetical website where you had a user and you had your name and someone from school finds it and takes it to school and 'oh Alice has got Chlamydia' and it's like it goes around the school like a joke. (Group 11, 16-20 years)

Yeah there is no $100 \%$ guarantee that the information that you provide is not being stored somewhere or seen by someone who is not supposed to see it, or kept on a server and like sent to China or something. (Group 4, 16-20 years)

These participants' apprehension of sharing personal information online highlights a general awareness of online scams and that sometimes there is a lack of certainty of who the author of some text is, how reliable the information is and where the data will be stored.

The same participants thought that technology provides the freedom to research and explore your issues in your own time which is considered much less terrifying than having to talk to someone straight away. Admitting that you have a medical concern or are struggling with an issue, is often the hardest thing to do so the option of dealing with it online and in privacy can be helpful as this participant describes:

Well that's the hardest part the majority of the time isn't it, is coming to terms with things yourself [...] and taking that step to maybe ask for a little bit of advice or a bit of help is usually the hardest thing to do. So if you can do that online or using technology without having to physically step through a door somewhere and let your face be seen for that first really hard step and, you know, acknowledging your situation, if you want to call it that. (Group 12, 21+years)
In a rural setting where communities are small, privacy is a significant issue hence the anonymity afforded by the internet was seen as a major advantage in using technology for health purposes. A participant who works as a nurse in the local area commented that embarrassment was a considerable deterrent for people seeking help in rural areas as they often know the medical staff. Overall, most participants thought user privacy was a very important feature of technology, one that could determine whether or not a person would want to engage with a particular website.

\section{Theme 7: technology can help raise awareness and peer support for people with health issues}

Focus groups from both regions discussed the usefulness of online discussions between people with similar conditions which could facilitate the formation of online communities. One participant felt it was a good opportunity to connect with others who had a similar medical condition to learn from their ideas and experiences:

Talking to someone that is going through the same thing is probably a lot better than talking to someone who's like 'Oh you are going to be fine mate', that doesn't know what they are going through (Group $11,16-20$ years)

With a widely dispersed population in rural communities and general lack of interaction with medical professionals or agencies, participants also described using social media to raise awareness of health conditions and especially increasing the visibility of mental health conditions which some participants report are still quite taboo in rural New Zealand.

I think technology could help in [LOCATION] as like more of an outreach thing because we are so rural and we are so separated from a lot of the big kind of city centres that have a lot more kind of like medical awareness [...] And I feel like technology can contribute to [LOCATION] by like opening that a lot more and letting some of those new ideas come in too [...] like I reckon especially things with mental health which is still unfortunately quite stigmatised here. (Group 11, 16-20 years)

However, one participant noted that attitudes are slowly changing and credited social media awareness campaigns with helping to increase visibility of mental health issues:

One thing I think is really important is probably, um, thinking rural communities is the mental health issue. I think it's really out there today, like it's talked about a lot more, it's-you see stuff on Facebook and Instagram or whatever, people doing posts about, 'Oh hey, it's blah, blah, blah, suicide awareness week', and things like that. And people grab it, share it and I think it's um, even if it is just flashed past a screen, it's maybe something a lot of our rural Kiwi blokes probably never seen before there was this type of stuff 
on technology, 'cos it can often be known as a taboo sort of subject... (Group 12, 21+years)

Another group of participants also discussed support for people with mental health issues:

For mental health with all this you know, all this information technology and the internet, there are communities that are building, that are actually really good at helping their community members deal with stuff like that. And they identify with it. Like how to fix it. (Group 3, 12-15 years)

I think that's why things like online tests and stuff is really good and sometimes people get nervous about illnesses or whatever, especially like mental ones. (Group 3, 12-15 years)

Especially with like anxiety, they could get really worried about going to see people and like actually, because that can be terrifying. (Group $3,12-15$ years)

The participants suggested that social media facilitates meeting and engaging with others, and online communities naturally develop around shared topics. Continuing from the previous theme, participants thought that peer support and awareness raising could still happen anonymously online which made it seem easier, and therefore, more likely to occur, especially when it involved topics like mental health.

\section{Theme 8: technology impacts social relationships}

Participants talked about using social media to organise social events including sporting events. Younger participants (12-15 years) in both regions mentioned that social media enhanced existing relationships and extended rural communities' opportunities for relationships given their isolated locations.

Actually it doesn't take away from the time you spend in real life it actually just adds to it. Because there are so many, especially like on Facebook and messaging, like that you can actually meet a whole lot more people and build really good relationships with them that you never would have met if stuff like that didn't exist. (Group 3, 12-15 years)

There was discussion among participants in several focus groups about how technology can negatively affect a person's social and cognitive development and some concerns about cyber bullying were raised. One group was particularly concerned with interpersonal communication:

I reckon interaction is a big one because a lot of us would just sit in this room and just look at our phones and we don't communicate with each other. (Group $2,21+$ years)

One 12-15years old focus group discussed how they enjoy their time at the beach or on bushwalks when they are in a particular area which has no cellphone reception. Although they are unable to use mobile phones in this area, they acknowledged that it forces them to interact with each other which they are less likely to do in other places when they can use their phones. They admitted that this was positive as they were outdoors and engaged with each other in a different way.

Yeah, so when we go out it's better because you actually have a conversation with people instead of sticking on your phone. - (Group 7, 12-15 years)

Social interconnectedness is a part of health and wellness. Several participants suggested that technology supported their social relationships, and enabled more opportunities for social interactions which may otherwise not have occurred due to living further away from town centres and from each other.

\section{DISCUSSION}

Participants in these two rural communities were positive about the potential greater role of technology in delivery of their healthcare, and beyond formal health services in also supporting the pursuit of wellness in their communities. Participants discussed ways in which technologies could improve access to health services and autonomy in pursuing health, such as through reducing the effect of stigma on willingness to engage, and the potential to find and engage with supportive peers. 'The internet' was the most commonly used and cited technology across all groups. Specific platforms such as Facebook, You Tube and Instagram were popular across all age groups although more predominantly with youth, for health information, social connection and how-to videos for example, how to strap your wrist to avoid injury in rugby. Apps were also commonly discussed, especially those related to healthy eating and exercise, and participants had used them for a variety of reasons from heart rate measurement to online appointment bookings. However, they also highlighted potential barriers, particularly that while technology might reduce the system costs of delivering health services, it requires users to buy technology to access these new services and that may be too expensive for some.

A strength of this study was the broad engagement with 73 youth and young people (out of 114 total participants), across 12 of 18 focus groups, in two remote rural regions of New Zealand. It is important to hear directly from young people themselves as access to healthcare impacts youth health and well-being. A further strength of the work was the engagement with communities in Northland which have a high proportion of Māori and there were deliberate efforts to ensure recruitment of Māori youth and young people to the focus groups. Māori consistently have poorer health outcomes across New Zealand so it was important to hear directly from Māori participants. Interaction started with hui (a gathering or meeting) with local healthcare providers about the proposed study and continued by recruitment of a Māori youth worker from the community and providing training in facilitation of 
the focus groups in that region. The study design cast a wide net regarding the potential role of technology to contribute to healthcare delivery in these communities. This was a deliberate approach, driven by a philosophical stance such that close engagement with the potential end-user communities to codesign any potential technology solutions is critical to successful implementation. We recognised limitations in this process, however, as we undertook the focus groups-the planned approach provided such a broad canvas on which groups could share their ideas that we did not obtain as much specificity and depth as we might otherwise have had, with a more targeted focus.

It is widely viewed that youth are positive about engaging with new technologies and that there is a growing role for these in the delivery of health and wellness services. Our findings compare similarly to results reported in the Long-term Conditions Young People Networked Communication study in the UK where youth aged 16-24 engaged with their clinicians digitally, especially results which indicated that young people preferred communicating with their clinician on sensitive issues via email or text. ${ }^{34}$

Likewise, it is often felt that technology may assist us in overcoming some of the challenges of delivery to rural and remote communities. As Hampshire $e t a l^{35}$ found in three African countries in urban and rural sites, seeking advice and information from the internet was an increasingly significant use of technology across all locations. Despite this, there is only limited evidence confirming that these views are even held by people in rural and remote communities. The work presented here provides a substantial further sample of the views of youth and young people in such communities, and on this occasion their views are largely concordant with those held by 'experts' and policy makers-who tend to be older, from dominant ethnic groups, and residing in major cities and national capitals. As such, this work provides support for the policy directions many countries are pursuing to develop such technology-supported approaches.

The key unanswered question in this field remains identification of the most acceptable, effective and costeffective ways to implement technology-based approaches in rural and remote communities. A critical target in any such work is ensuring that this results in a clear reduction of disparities in health-in particular of improving rates of health and wellness in rural and remote communities and also importantly in the minority ethnic communities and socioeconomically disadvantaged in those regions who are the least well served by our health systems to date.

Acknowledgements The researchers thank our clinical partners in Northland and in Southland who kindly contributed to the design and success of this study. We would also like to thank the people in Northland and Southland, who volunteered to participate in the focus groups and shared their opinions and insights.

Contributors DRB: Primary conception and design of the work, oversight of data acquisition, analysis and interpretation processes, drafting the discussion and critical revision of other sections of the manuscript, final approval of the version to be published. KvK: Primary conception and design of the work, oversight of data acquisition, analysis and interpretation processes, revising the manuscript for important intellectual content, final approval of the version to be published. AT: Primary lead on the thematic analysis, contributions to the drafting of the method and results sections of the work, final approval of the version to be published. JD: Direct supervision of the research assistants conducting the focus groups, contribution to the oversight of data analysis and interpretation processes, revising the manuscript for important intellectual content, final approval of the version to be published. HE: Contributions to the conception and design of the work, oversight of data acquisition, analysis and interpretation processes, revising the manuscript for important intellectual content, final approval of the version to be published.

Funding This work was supported by the Auckland University of Technology Strategic Research Investment Fund.

\section{Competing interests None declared.}

Patient and public involvement Patients and/or the public were involved in the design, or conduct, or reporting, or dissemination plans of this research. Refer to the Methods section for further details.

Patient consent for publication Not required.

Ethics approval Ethical approval was obtained from the Auckland University of Technology (AUT) Ethics Committee (15/255).

Provenance and peer review Not commissioned; externally peer reviewed.

Data availability statement All data relevant to the study are included in the article or uploaded as online supplementary information.

Open access This is an open access article distributed in accordance with the Creative Commons Attribution Non Commercial (CC BY-NC 4.0) license, which permits others to distribute, remix, adapt, build upon this work non-commercially, and license their derivative works on different terms, provided the original work is properly cited, appropriate credit is given, any changes made indicated, and the use is non-commercial. See: http://creativecommons.org/licenses/by-nc/4.0/.

\section{ORCID iDs}

Duncan R Babbage http://orcid.org/0000-0002-9259-9246

Kirsten van Kessel http://orcid.org/0000-0002-7069-172X

Juliet Drown http://orcid.org/0000-0003-4803-9249

Hinemoa Elder http://orcid.org/0000-0003-0311-6626

\section{REFERENCES}

1 Brabyn L, Barnett AR. Population need and geographical access to general practitioners in rural New Zealand. $N Z$ Med $J$ 2004;117:1-13.

2 Ford JA, Wong G, Jones AP, et al. Access to primary care for socioeconomically disadvantaged older people in rural areas: a realist review. BMJ Open 2016;6:e010652.

3 Fearnley D, Kerse N, Nixon G. The price of 'free'. Quantifying the costs incurred by rural residents attending publically funded outpatient clinics in rural and base hospitals. J Prim Health Care 2016;8:204.

4 Jensen EJ, Mendenhall T. Call to action: family therapy and rural mental health. Contemp Fam Ther 2018;40:309-17.

5 Strasser R, Neusy A-J. Context counts: training health workers in and for rural and remote areas. Bull World Health Organ 2010;88:777-82.

6 Voluntary bonding scheme. Available: https://www.health.govt.nz/ our-work/health-workforce/voluntary-bonding-scheme [Accessed Feb 2020].

7 Wong DL, Nixon G. The rural medical generalist workforce: the Royal New Zealand College of general practitioners' 2014 workforce survey results. J Prim Health Care 2016;8:196.

8 Obertová Z, Hodgson F, Scott-Jones J, et al. Rural-Urban differences in prostate-specific antigen (PSA) screening and its outcomes in New Zealand. J Rural Health 2016;32:56-62.

9 Williams F, Jeanetta S, James AS. Geographical location and stage of breast cancer diagnosis: a systematic review of the literature. $J$ Health Care Poor Underserved 2016;27:1357-83.

10 Brewer N, Pearce N, Day P, et al. Travel time and distance to health care only partially account for the ethnic inequalities in cervical cancer stage at diagnosis and mortality in New Zealand. Aust N Z J Public Health 2012;36:335-42.

11 Larkins S, Johnston K, Hogenbirk JC, et al. Practice intentions at entry to and exit from medical schools aspiring to social accountability: findings from the training for health equity network graduate outcome study. BMC Med Educ 2018;18:261. 
12 Bradford NK, Caffery LJ, Smith AC. Telehealth services in rural and remote Australia: a systematic review of models of care and factors influencing success and sustainability. Rural Remote Health 2016;16:3808.

13 Batastini AB, King CM, Morgan RD, et al. Telepsychological services with criminal justice and substance abuse clients: a systematic review and meta-analysis. Psychol Serv 2016;13:20-30.

14 Bursell S-E, Zang S, Keech AC, et al. Evolving telehealth reimbursement in Australia. Intern Med J 2016;46:977-81.

15 Neiger BL, Thackeray R, Van Wagenen SA, et al. Use of social media in health promotion. Health Promot Pract 2012;13:159-64.

16 Free C, Phillips G, Watson L, et al. The effectiveness of mobilehealth technologies to improve health care service delivery processes: a systematic review and meta-analysis. PLoS Med 2013;10:e1001363.

17 Pezzullo S, Mitchell L. Financial and externality impacts of high-speed broadband for telehealth (report for the Department of broadband, communications and the digital economy, Commonwealth of Australia). Canberra, Australia: Access Economics, 2010. http:// ict-industry-reports.com.au/wp-content/uploads/sites/4/2010/07/ 2010-Financial-Externality-Impacts-of-High-Speed-Broadband-forTelehealth-2010.pdf

18 Medina EL, Loques Filho O, Mesquita CT. Health social networks as online life support groups for patients with cardiovascular diseases. Arq Bras Cardiol 2013;101:e39-45.

19 Moorhead SA, Hazlett DE, Harrison L, et al. A new dimension of health care: systematic review of the uses, benefits, and limitations of social media for health communication. J Med Internet Res 2013;15:e85.

20 Moore K, Cottrell E, Chambers R. Facebook in general practice: a service evaluation in one health economy. BJGP Open 2018;1:bjgpopen17X101181.

21 Crilly P, Hassanali W, Khanna G, et al. Community pharmacist perceptions of their role and the use of social media and mobile health applications as tools in public health. Res Social Adm Pharm 2019;15:23-30.

22 Chang F, Paramsothy T, Roche M, et al. Patient, staff, and clinician perspectives on implementing electronic communications in an interdisciplinary rural family health practice. Prim Health Care Res Dev 2017;18:149-60.
23 Kuester A, Niemeyer H, Knaevelsrud C. Internet-Based interventions for posttraumatic stress: a meta-analysis of randomized controlled trials. Clin Psychol Rev 2016;43:1-16.

24 Backhaus A, Agha Z, Maglione ML, et al. Videoconferencing psychotherapy: a systematic review. Psychol Serv 2012;9:111-31.

25 Musiat P, Goldstone P, Tarrier N. Understanding the acceptability of e-mental health--attitudes and expectations towards computerised self-help treatments for mental health problems. BMC Psychiatry 2014;14:109.

26 Welch V, Petkovic J, Pardo Pardo J, et al. Interactive social media interventions to promote health equity: an overview of reviews. Health Promot Chronic Dis Prev Can 2016;36:63-75.

27 Wootton BM, Titov N, Dear BF, et al. The acceptability of Internetbased treatment and characteristics of an adult sample with obsessive compulsive disorder: an Internet survey. PLoS One 2011;6:e20548.

28 Carper MM, McHugh RK, Barlow DH. The dissemination of computer-based psychological treatment: a preliminary analysis of patient and clinician perceptions. Adm Policy Ment Health 2013;40:87-95.

29 Taiminen H, Saraniemi S. Acceptance of Online Health Services for Self-Help in the Context of Mental Health: Understanding Young Adults' Experiences. J Technol Hum Serv 2018;36:125-39.

30 QuickStats about a place. Census, 2013. Available: http://archive. stats.govt.nz/Census/2013-census/profile-and-summary-reports/ quickstats-about-a-place.aspx\#13068 [Accessed Dec 2018].

31 Braun V, Clarke V. Using thematic analysis in psychology. Qual Res Psychol 2006;3:77-101.

32 Braun V, Clarke V. Successful qualitative research: a practical guide for beginners. Sage, 2013.

33 Braun V, Clarke V, Terry G. Thematic analysis. Qual Res Clin Health Psychol 2014;24:95-114.

34 Griffiths FE, Armoiry X, Atherton H, et al. The Role of Digital Communication in Patient-clinician Communication for NHS Providers of Specialist Clinical Services for Young People [The Long-term Conditions Young People Networked Communication (LYNC) Study]: A Mixed-Methods Study. Health Services and Delivery Research 2018;6:1-270.

35 Hampshire K, Porter G, Owusu SA, et al. Informal m-health: how are young people using mobile phones to bridge healthcare gaps in subSaharan Africa? Soc Sci Med 2015;142:90-9. 